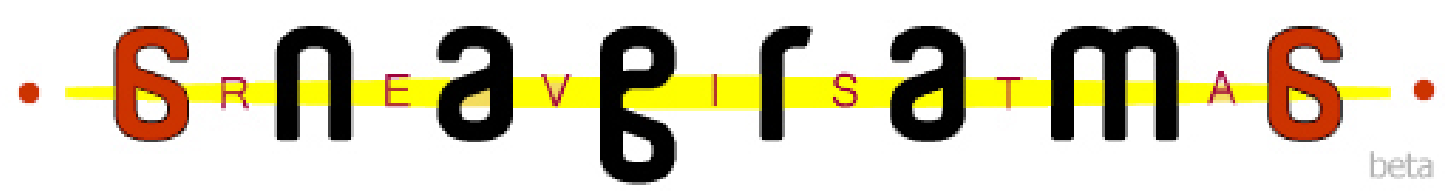

\section{A Interpretação do Gigante: jornalismo e política em Veja}

Aline Uogt ${ }^{7}$

Camilla Milder ${ }^{2}$

Franciele Fonseca ${ }^{3}$

Caroline Casali $^{4}$

\section{Resumo}

A relação entre política e mídia é, a longa data, de interdependência. A mídia necessita da política - bem como de outros campos sociais - pois não possui discurso próprio; seu fazer consiste na mediação dos discursos dos outros campos. E a política depende da mídia praça pública contemporânea - para se faz-conhecer, atingindo milhares de pessoas. $\mathrm{O}$ objetivo deste artigo é analisar essa relação entre a política e o jornalismo da revista Veja através do discurso dessa mídia impressa sobre o caso Renan Calheiros. A análise demonstra, em geral, que a revista, ao tratar de política, apresenta um discurso marcado pela subjetividade, evocada pelo uso de adjetivações e autoreferências.

Palauras-chaue: Discurso; Subjetividade; Mídia impressa revista.

"Perde-se um Brasil, Senhor, porque alguns ministros de Sua Majestade não vêm cá buscar nosso bem. Vem cá buscar nossos bens."

Pe. Antonio Vieira (1943)

\footnotetext{
${ }^{1}$ Acadêmica do terceiro semestre do Curso de Comunicação Social - Jornalismo do CESNORS/UFSM.

${ }^{2}$ Acadêmica do terceiro semestre do Curso de Comunicação Social - Jornalismo do CESNORS/UFSM.

${ }^{3}$ Acadêmica do terceiro semestre do Curso de Comunicação Social - Jornalismo do CESNORS/UFSM.

${ }^{4}$ Professora Assistente do Departamento de Ciências da Comunicação do CESNORS/UFSM. Jornalista formada pela UFSM e Mestre em Ciências da Comunicação pela UNISINOS.
} 


\section{Introdução:}

Sabe-se que a política depende da mídia para divulgar suas atuações e legitimá-las, sendo este o seu suporte. Segundo Rubim (2000), o poder político e a política se relacionam em uma nova e contemporânea circunstância societária, estruturada em rede e ambientada pela mídia.

A definição dada por Aristóteles para definir o homem como 'zoon politikon' homem é por natureza um animal político - não quer dizer que simplesmente por viver numa sociedade o ser humano exercia 'política', mas por ter uma compreensão sobre governo e liberdade. Segundo estudos de Peruzzolo apud Casali (2003), a atividade política torna-se essencialmente uma atividade comunicacional, que se desenvolve, necessariamente no contato com os destinatários da ação política.

Contudo, para além da apresentação da política, a mídia tem investido na própria construção de cenários políticos. Toma-se como exemplo a presença dos meios de comunicação na Campanha de Diretas Já (1984), impeachment de Collor (1992) e as eleições e debates eleitorais das campanhas à Presidência do Brasil (2002 e 2006). Para Gomes (1999), o fenômeno da imagem política parece ter surgido junto com a vida pública, no entanto, o que se tem evidenciado é a sua ligação com a esfera da visibilidade e com os meios de comunicação. É justamente essa ligação entre política e visibilidade midiática o objeto de análise deste artigo, que investiga o discurso da revista Veja sobre o Caso Calheiros.

De acordo com o histórico divulgado em sua própria página na internet ${ }^{5}$, a revista Veja começou a circular em setembro de 1968, criada pelos jornalistas Victor Civita e Mino Carta, quando os índices de analfabetismos no país ainda eram altos. Desde seu lançamento, a revista já previa trabalhar com um discurso analítico e interpretativo sobre a sociedade brasileira, "incorporada ao movimento, procurou descrevê-lo e interpretá-lo para seus leitores (...), Veja acompanhou cada acontecimento procurou desvendar suas chaves explicativas, colocou-os em perspectiva para seus leitores". A revista, criada nos moldes da revista americana TIME, é lida, hoje, por mais de 4,5 milhões de pessoas, sendo 69\% pertencentes às classes A e B. A revista é quinzenal e publicada pela Editora Abril.

A partir de maio de 2007, algumas edições da revista Veja privilegiaram, discursivamente, a apresentação do político José Renan Vasconcelos Calheiros, filiado ao

\footnotetext{
${ }^{5}$ Disponível em: http://vejaonline.abril.com.br. Acesso em: 22 de março de 2008; 08:49.
} 
PMDB (Partido do Movimento Democrático Brasileiro) e então presidente do Senado Federal, e seu envolvimento em escândalos políticos. A primeira denúncia, feita pela própria Veja, afirmava que o senador tivera suas despesas pessoais pagas pelo lobista Cláudio Gontijo, ligado a empreiteira Mendes Júnior. O dinheiro seria utilizado para o pagamento da pensão de sua filha, fruto de um relacionamento (extraconjugal) com a jornalista Mônica Veloso, e também para o aluguel do apartamento onde moravam. O assunto ganhou destaque na revista, que até então se limitava a explorar a 'Operação Navalha' - operação que implodiu a quadrilha que assaltava verbas públicas, onde as ligações mais notórias seriam com o próprio presidente do Senado - dando lugar às irregularidades apresentadas nos documentos de Renan Calheiros na declaração de suas despesas.

A pedido do PSOL (Partido Socialismo e Liberdade), o caso seguiu para o Conselho de Ética do Senado, onde fora exigida a quebra do decoro parlamentar. Seguemse a este ocorrido, outras denúncias, como a de que a Schincariol ${ }^{6}$ teria recebido benefícios de Renan, seu envolvimento com grilagem em terras de Alagoas, e de que houvera "armação" no fato de o frigorífico que comprara a maior parte do gado vendido por Renan - de onde vinha sua fonte extra de dinheiro - ter sido assaltado um dia antes da entrega de documentos para inspeção do caso. Em 04 de maio, ainda, Veja acusa o presidente do Senado teria usado 'laranjas' para a compra de emissoras de rádio em Alagoas, no valor de R \$ 2,5 milhões. Trata-se aí da mídia fiscalizando o poder e demonstrando o seu próprio poder em construir cenários políticos e agendar os temas sobre os quais a sociedade deve discutir quando acerca da política. Este quadro de construção discursiva do cenário político brasileiro, sobre o caso Renan Calheiros, é objeto de análise neste artigo.

\section{0 gigante e as denúncias: Renan Calheiros por Ueja}

A Revista Veja, assim como qualquer veículo de comunicação, tem um jeito próprio de enunciar e busca legitimar, em cada edição, suas próprias marcas discursivas. No entanto, muitas vezes, acaba por incorporar uma linguagem peculiar ao veículo e deixa de lado o compromisso com a linguagem jornalística. Sabe-se que um jornalismo sério prima pela imparcialidade (demarcada pela apresentação dos vários lados da notícia), pela valorização do interesse público, e pela ética.

\footnotetext{
${ }^{6}$ Empresa brasileira de bebidas, com marcas conhecidas como Nova Schin e Primus. Disponível em:
} www.schincariol.com.br. Acesso em: 22 de março de 2008. 
O Brasil vive, há anos, a publicização de uma série de denúncias evolvendo seus principais políticos em atos ilícitos, renúncias, demissões e cassações. Nestes acontecimentos, a mídia esteve presente. Apesar de despertar o conhecimento e a consciência da política brasileira, não somente em eleitores, mas na população em geral, os meios de comunicação têm criado cenários políticos particulares, escolhendo e moldando as notícias, construindo e desconstruindo imagens. Na revista Veja esses cenários são demarcados por determinadas escolhas discursivas, que serão abaixo analisadas.

\section{Uso de Adjetiuações}

A objetividade é um atributo básico ao qual o jornalista precisa obedecer. Erbolatto (1991:56) ilustra com precisão essa característica jornalística:

Outra característica da notícia é a objetividade. Deve ser publicada de forma sintética, sem rodeios e de maneira a dar uma noção correta do assunto focalizado. Quem colhe dados, observando o local ou entrevistando pessoas capacitadas a proporcionar informações para a matéria, deve agir com isenção de ânimo. Honestidade e imparcialidade são atributos exigidos do repórter.

Contudo, na matéria 'Sociedade Secreta', da edição 2020, percebe-se o quanto a linguagem da revista Veja segue carregada de adjetivações, a exemplo dos seguintes trechos: 'Os negócios de Renan são clandestinos, irregulares, forjados de modo a manter o anonimato dos envolvidos' (p.60). "Dessa forma, com um contrato de gaveta, laranjas e pilhas de dólares e reais em envelopes pardos, o senador iniciou sua incursão no mundo empresarial das comunicações” (p.63). "Em seu lugar, Renan Calheiros coloca primeiro o primo e empresário Tito Uchoa, o mesmo que servira de pombo-correio do negócio original" (p.64). A revista emite juízos de valor e não segue às regularidades fixadas pelo jornalismo, nas quais a objetividade é princípio básico.

(...) Os jornalistas não são apenas observadores à distância dos acontecimentos. Imaginarse-ia que, guardados numa posição estratégica, pudessem contemplar a "colina dos acontecimentos", com a devida isenção, e em um espaço que os poupasse da temperatura inerente ao próprio ambiente de produção da realidade. Porém, como se sabe, mesmo à distância, mobilizam seus dotes de ubiqüidade e de onisciência, fazendo uso de fórmulas narrativas que os proporcionem ser colocados no seio das cenas, e também fazendo-os viajar para a condição de atores privilegiados (TRAQUINA, 2005:11). 
É justamente nesse seio da cena que a revista de posiciona. Não basta a ela apresentar denúncias, é preciso mostrar que a revista tem experiência (e por que não dizer competência - ao que parece jurídica e política) para julgar as denúncias, condenando Calheiros. Na edição 2010, de 30 de maio de 2007, a revista segue apresentando uma série de acusações e interpretações sobre as atitudes de Renan e seu envolvimento com o diretor da construtora Mendes Júnior - como sugere o próprio título da matéria: 'Senador e o Lobista'. Veja afirma: 'o senador tem dito que são apenas conhecidos, mas são mais do que isso' (referindo-se a Zuleido), segue-se ainda: ' a situação de Renan Calheiros, porém, é mais complicada do que sai intimidade com Zuleido Veras - o dono da construtora Gautama, pivô da Operação Navalha e '(...) o senador tem outro amigo explosivo no submundo. '

A exposição do assunto pela revista revela especulações em Veja, que interpreta para seus leitores o quadro político que ela mesma apresenta. Giogio Grossi (1985:150) diz que:

A comunicação desempenha fundamentalmente uma função de adaptação entre governantes e governados, entre partidos e eleitores, com especial referência à circulação autoritária de valores fazendo uso de todos os instrumentos e mecanismos que o universo da comunicação pode proporcionar.

Veja afirma que o senador Renan Calheiros e Zuleido são mais do que conhecidos, como se a própria revista fosse uma fonte próxima à vida do Senador. O uso de adjetivações para o 'outro amigo explosivo no submundo' mostra a circulação de valores que deixa subentendida a relação de Calheiros com um local onde se verifica a proliferação de atividades consideradas anti-sociais, criminais.

\section{Uso da Autoreferência}

Ao longo da análise, constata-se que Veja utiliza-se de mais um recurso: a autoreferência. Com isso, o jornalismo da revista adquire certo 'poder' diante dos fatos sociais, quando o mais acertado - em consideração ao jornalismo - seria o uso da neutralidade. Na edição 2012, de 13 de junho de 2007, Veja continua a destacar o caso Renan Calheiros, atribuindo para si toda a exclusividade das descobertas políticas, com expressões como: 'Veja revelou', 'Veja apurou', 'À Veja ele confirmou'. 
Na matéria da edição 2020, intitulada 'Sociedade Secreta', a revista enuncia ainda: 'Veja teve acesso a documentos que mostram como o senador criou uma empresa de comunicação' (p.60). Na edição 2011, encontram-se trechos com as seguintes enunciações: 'Como fizera a VEJA antes, ele garantiu que o dinheiro era seu. E ainda na matéria 'Eles são unha e carne',edição 2011, Veja afirma - e se auto-afirma enquanto investigadora do caso - 'a revista obteve cópias de contratos em que esses favores estão registrados'.

Através das enunciações transcritas, fica claro que a revista atribui a si mesma além da capacidade de julgamento - uma competência investigativa.

Chamamos atenção para as maneiras de como este poder de dizer se autonomeia e, ao mesmo tempo, se auto-referencia. Em seguida, como constitui uma "testemunha sempre autorizada" daquilo que viu, mostrou e comentou sobre o espaço da política (FAUSTO NETO, 1995:12).

A revista Veja deixa assim a imparcialidade jornalística de lado e prima por um discurso subjetivo, repleto de adjetivações, juízos de valor, e auto-referências à sua capacidade de não só apresentar denúncias, mas também investigá-las. Veja assim age no sentido de manipulação midiática de que fala Weber (2000, p.140), "a comunicação mascara, reduz e omite informações, verdades e realidades e controla os meios de comunicação, produzindo informações e propaganda". A revista cumpre assim seu papel de editar o que se passa no mundo e não refletir.

\section{OEspetáculo Particular}

A revista Veja, em suas edições sobre o Caso Renan Calheiros, também expõe a vida particular do senador, analisa suas relações sociais, de forma a espetacularizar sua vida e atuação política. Debord (1967), em seu livro Sociedade do Espetáculo, fala justamente sobre a construção de imagens em uma sociedade que prima o tempo todo pela aparência.

O espetáculo não é um conjunto de imagens, mas uma relação social entre as pessoas, mediada por imagens. As imagens que se destacam de cada aspecto da vida fundem-se num fluxo comum, no qual a unidade dessa mesma vida já não pode ser restabelecida. A realidade considerada parcialmente apresenta-se em sua própria unidade geral como um pseudomundo à parte, objeto de mera contemplação (DEBORD, 1967).

Mônica Veloso, jornalista de 38 anos que viveu um romance com o senador Calheiros e teve uma filha com ele, em entrevista a revista Veja, defende-se do fato de 
estar sendo apresentada como uma pessoa desclassificada, "falam como se eu não tivesse profissão, nem família, nem meio de vida, como se fosse uma chantagista", diz Mônica, criticando a maneira como sua vida foi explorada pela mídia de forma a fazer dela uma narrativa de telenovela, um show circense.

A imagem é algo que nos parece ser. Para Gomes apud Casali (2003), a imagem é uma tentativa de nos aproximarmos da essência e do que realmente é o objeto, marcas que são tomadas como o seu caráter. No entanto, cada ato pode ser lido de uma mentira, cada indivíduo pode interpretar o seu modo, assim como o contexto. A imagem não reflete, portanto, a personalidade do ator social, revela sim um personagem criado dentro da narrativa discursiva. Na narrativa de Veja, a vida social de Calheiros e seus pares é conduzida como na teledramaturgia - com enfoque ao enredo amoroso e as tramas de um personagem que traía com freqüência sua esposa. Na entrevista com Mônica Veloso, na edição 2012, ao invés de enfocar as denúncias sobre o dinheiro, a participação do lobista e outras transações, Veja demonstrava-se mais interessada na freqüência com que a jornalista e Calheiros se encontravam e na intensidade da relação. 'Ficávamos a sós, se é isso que você quer saber', respondeu Mônica Veloso à insistência do jornalista. Roger-Gérard Schwatzenberg (1978) apresenta de forma contundente essa relação entre um cenário político antes feito de idéias e ações e hoje espetacularizado via mídia: "a política, outrora, era de idéias. Hoje, é pessoas. Ou melhor, personagens" (Schwatzenberg, 1978).

\section{O discurso icônico: imagens do escândalo}

A análise do discurso da revista passa ainda pelo texto icônico, além do texto verbal. Afinal, a fotografia é o meio do primeiro contato que o leitor empreende com a revista. Em se tratando de Veja, é possível identificar que a revista usa de fotografias, aliando-as aos sentidos pretendidos com o texto verbal.

A capa da revista em sua edição 2020 apresenta Renan Calheiros sentado sobre uma laranja, montagem que remete ao sentido de que Calheiros mantinha relações com laranjas ${ }^{7}$. A expressão do político nesta fotografia remete ao sentido de serenidade, como se Renan estivesse pouco preocupado com as operações políticas que vinha conduzindo, ou como se estivesse em uma posição confortável frente às acusações ou ao cenário político

7 Pessoa física ou pessoa jurídica que 'empresta' o nome para fazer negociações. Disponível em: www.fazenda.gov.org. 
brasileiro. Cabe destacar que, ao adotar a montagem fotográfica, a revista escolhe não apenas retratar fatos cotidianos, mas prima pela produção de uma situação, de um cenário.

Outro sentido interessante a que a revista remete em sua linguagem icônica é o destaque à figura política de Renan e não do Senado como um todo ou dos envolvidos com ele nos escândalos apresentados. Para isso, Veja se utiliza do enquadramento em close, demarcando bem as expressões faciais de Renan.

O político é apresentado iconicamente enquanto figurão do Senado, o que é destacado pela fotografia da cadeira da Presidência e por seus trajes formais e cenários oficiais. Suas expressões faciais destacam, na maioria das fotografias, o conforto em se ocupar de tal cargo e, às vezes, a apreensão de estar sob suspeita.

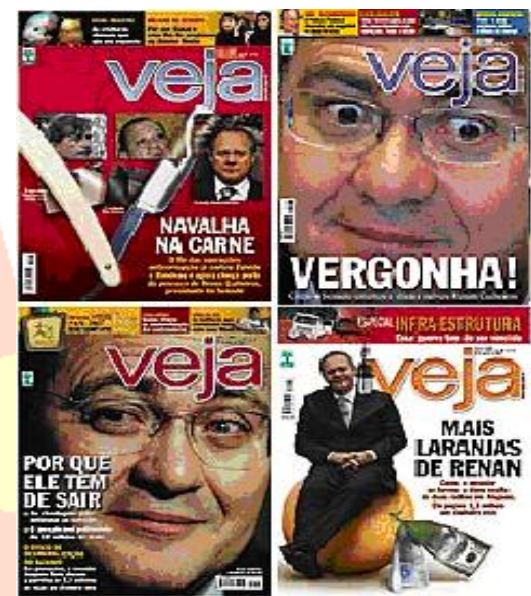

Quadro 1 - Capas das edições da VEJA sobre o Caso Calheiros.
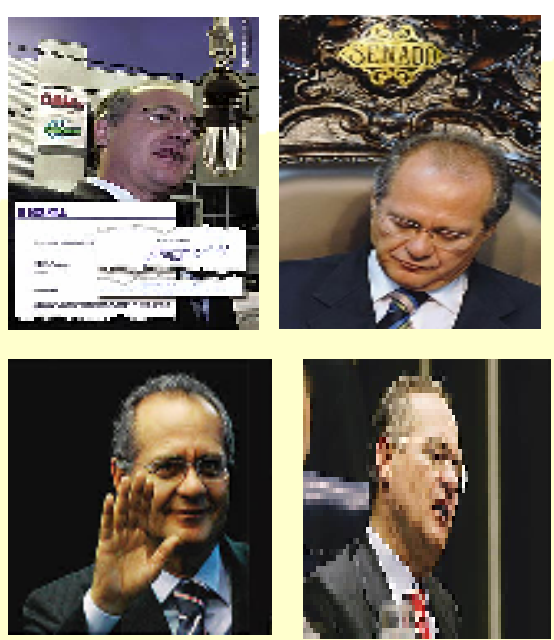

Quadro 2 - Expressões Faciais de Renan Calheiros.

\section{?. CONSIDERAÇÔES FInRIS}

Sabe-se que não é apenas o campo político que sofre hoje interferência midiática, ou seja, outras instituições como a família, a educação e a religião também estão sendo atravessadas pela mídia - como exemplo têm-se canais de conteúdo religioso e de propagação de igrejas e o ajustamento da rotina da família aos horários televisivos. Por outro lado, a política é uma atividade conjunta dos cidadãos desenvolvida na esfera da fala, logo, é essencial a ela uma atividade comunicacional que permita o contato dos políticos com os destinatários da ação política - o que acontece hoje via meios de comunicação de massa. 
Nessa inter-relação entre política e mídia, os meios de comunicação de massa têm não só apresentado ações e personagens políticos, mas também construído cenários. E a revista Veja, enquanto grande mídia brasileira, contribui nessa construção através de um discurso marcado por adjetivações, auto-referência e espetacularização.

\section{Referências Bibliográficas}

CASALI, Caroline. A imagem dos candidatos à presidência no discurso da Veja. Monografia de conclusão de curso, universidade Federal de Santa Maria (UFSM), CCSH, Curso de Comunicação Social - Jornalismo, 2003.

DEBORD, Guy. A Sociedade do Espetáculo. Editora Afrodite. Lisboa, 1967.

ERBOLlATTO, Mario. Técnicas de Codificação em Jornalismo. São Paulo: Ática, 1991.

GOMES, Wilson. Esfera pública política e media II In: RUBIM, A A C et al. Práticas discursivas na cultura contemporânea. São Leopoldo: Unisinos, Compôs. 1999.

GROSSI, Giogio apud Souvenir Maria Graczyk Dornelles. O espaço das relações públicas no cenário da comunicação política. Disponível em: http://reposcom.portcom.intercom.org.br/bitstream/1904/18763/1/2002_NP5DORNELLES .pdf

NETO, Antônio Fausto. O Impeachment Da Televisão. Rio de Janeiro: Diadorim, 1995.

RUBIM, Antonio Albino Canelas. Comunicação e política. São Paulo, Hacker Editores, 2000 .

RUBIM, Antonio Albino Canela. Novas Configurações das Eleições na Idade Mídia.

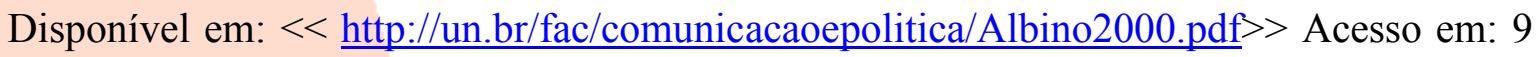
de agosto 2007. 
SCHWARTZENBERG, Roger-Gérard. O Estado Espetáculo, Rio de Janeiro/São Paulo, Difel, 1978.

TRAQUINA, Nelson. O Estudo Do Jornalismo No Século XX. São Leopoldo: UNISINOS, 2005 .

VIEIRA, Antonio. Sermões. Reprodução fac-similada da edição de 1682. Organização do Pe. Augusto Magne. São Paulo: Anchieta, 1943. 3 vol.

WEBER, Maria Helena. Comunicação e espetáculos da política. Porto Alegre: EDUFRGS, 2000. 